\title{
Formation factors of the architecture of multi- level public spaces on the example of the countries of North America and Asia
}

\author{
Ekaterina Pokka ${ }^{1[0000-0003-2111-4712]}$, Evgeny Ponomarev ${ }^{1 *[0000-0002-0813-5669]}$, and Viktoria Timakova ${ }^{2}$ \\ ${ }^{1}$ Kazan State University of Architecture and Engineering,420043 Kazan, Russia \\ ${ }^{2}$ JSC Transneft-Prikamye, 420081Kazan, Russia
}

\begin{abstract}
The goal of the study is to identify characteristic features of multilevel public spaces (MPS's) and perspectives of their development, based on complex analysis of their formation in the late $20^{\text {th to }}$ early $21^{\text {st }}$ centuries.Authors were able to identify architectural planning factors of MPS formation and functioning in North America and Asia by summarizing the experience in creation of multilevel public spaces by architectural planning means.

Keywords. Pedestrian space, multi-level pedestrian space, vertical division of streets, pedestrian level.
\end{abstract}

\section{Introduction}

Urban space consists of transportation system, pedestrian system, and urban fabric - the volumes of buildings and city quarters- acting as a filler.The density of urban environment increases with the time, and the elements of urban environment start to permeate each other.Public spaces become more populated and functionally saturated, which results in the deformation of city's architectural spacein terms of its compaction [1]. As a consequence, the emergence of multilevel public spaces becomes typical for all large cities and megapolises, where they function as various urban systems - pedestrian networks, transport framework, urban fabric, etc. [2].

Multilevel public spaces are the element of pedestrian networks,divided by levels and locations. An MPS is usually a pedestrian-only territory independent of automotive traffic, however, in some situations, an MPS and automotive traffic can beconnected.Levels of an MPS are intertwined via various indoor and outdoor pedestrian spaces in continuous motion, creating dynamicsof urbanenvironment.The system of MPS includes pedestrian bridges, elevators and escalators, roof terraces, atria, and large range of indoor and outdoor spaces open for public [3]. Intersections of pedestrian communications within the multilevel public space create an evolved mobile network acting as a single urban development system, while preserving its architectural variety depending on its place within the urban fabric [4].

In this study we analyzeMPS formation in four diametrically opposite and contrasting countries of North America and Asia. Their well-developed pedestrian system is a good example worthy of application in the global and domestic architectural practice, including

${ }^{*}$ Corresponding author: ponom_argo@mail.ru 
Russia. Identification of factors underlying the formation of MPS's, and theoretical perception of MPS's existing in these countries poses a special interest in the context of their substantially different cultural environments [5].

A knowledge of MPS implementation experience will allow us to identify the factors of architectural formation and to grasp the concept of a multilevel public space, illustrated by the example of the USA, Canada, China and India -four completely different countries of North America and Asia.Thesubjects selected for the study can be characterized by strong ties between architectural solutions of an MPS and the cultural code of the region [6]. The evolved pedestrian system of these MPS'scan be viewed as the reference standard for Russian megapolises.

Thus, in 1988, construction of skywaynetworks in several North America cities resulted in the increase in property value [7]. This experience resulted in further studies on the impact of skyways in developing countries. In Asia, multilevel pedestrian systems were usually formed due to the absence of proper sidewalks and the abundance of street merchants using any spare patches of the pavement as an improvised sales outlet [8]. The operation of pedestrian crosswalks made it possible to solve several environmental problems, such as street pollution, heavy traffic,deteriorating condition of roads, etc. Besides, MPS implementation has also resulted in additional revenue from tourism.

This study is aimed at identification of architectural and planning factors influencing the formation of an MPS.

\section{Materials and methods}

For this work,we conducted the in-depth study and comparative analysis of theoretical sources and actual examples of MPS implementation, fusing the information on foreign practices of MPS realization in culturally contrasting countries. The concept proposed by Leonardo DaVinci was one of the historical references studied. The concept suggested the vertical differentiation of a city street space into several tiers, where upper tiers would be designed exclusively for pedestrians and lower tiers would be intended for carriages, services, and trade[9].

We also studied the architectural projects of the avantgarde art, used as the protypes for future pedestrian systems.Modern architects consciously refer to the early avantgarde concepts, such as flying cities and horizontal skyscrapers [10], while developing the projects of multi-level public space. The continuity of pedestrian systems development in modern cities can be vividly represented by projects realized in Minneapolis and Calgary in 19501960. Each project of pedestrian system has its history. In Minneapolis it was the product of collaboration between architects and municipal administration [11]. In Calgary the system was designed by architects inspired by the ideas of Soviet avantgarde of the $1920^{\mathrm{s}}$ and by concepts of urbanist city-planners realizing new architectural solutions [12].

The two most prominent names in the development of multi-level pedestrian systems are Victor Gruen and Vincent Ponte. They have focused on the detailed design of new types of over- and underground pedestrian systems. Their ideas were used for construction of pedestrian systems in Saint Paul, Minneapolis and Montreal, laying the foundations for modern systems like SkyWay, La Ville Souteraine, Calgary +15, etc. [13].

The concept of all-encompassing 3D pedestrian network in a city has emerged in the beginning of 1900 s as a way to reduce traffic jams within city centers with high population density [14]. The active developmentof MPS'sin the world practice took place in 1950-60s, when many American cities had started to experiment with introduction of multilevel transport networks, parkings, andto create pedestrian-only urban areas.

Currently, we can see a growing interest in the global architectural and city planning community to the MPS implementation within urban environment. LisinaO.A. in [15] discusses the emergence and evolution of multilevel pedestrian spaces, offering a step-by- 
step review of historical backgrounds of pedestrian spaces formation - from single- to multilevel ones. The principles of multilevel pedestrian space formation are also discussed in papers by Wagner E.A. [16], Sokolova N.V.and Sukhova O.I. [17].

For this study we reviewed the modern examples of multilevel pedestrian spacein the countries of North America and Asia. Extensive overground pedestrian systems parallel to original streets can be found in North American cities such as Minneapolis, Saint Paul, and Calgary, while Montreal and Toronto can boast ramified underground networks. In Asia, multilevel overground systems are usually formed by pedestrian crosswalks. To illustrate, in the last decade almost 40 overground pedestrian walkways have been constructed in Mumbai in order to reduce the load onground levels. Unfortunately, in spite of the growing number of such structures they get little critical academic attention, considering their role in formation of modern urban environment [18].

\section{Results}

The first overground pedestrian system in America was created in the city of Saint Paul (fig.1). Later, this system was used as a prototype for the SkyWayin Minneapolis (fig.2).

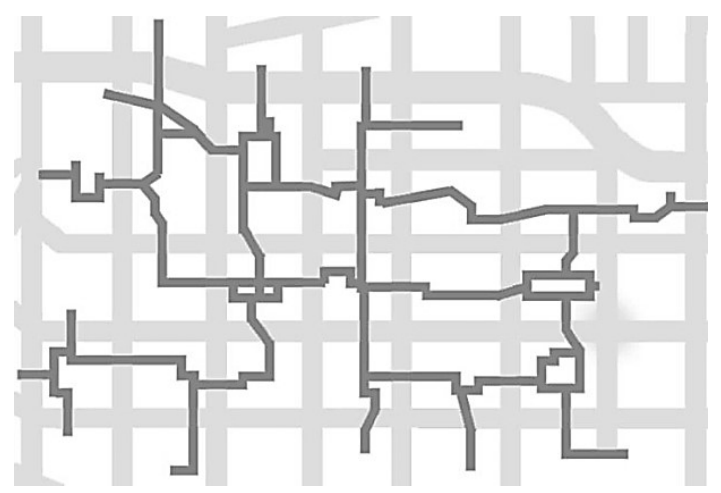

Fig. 1. SkyWay in Saint Paul.

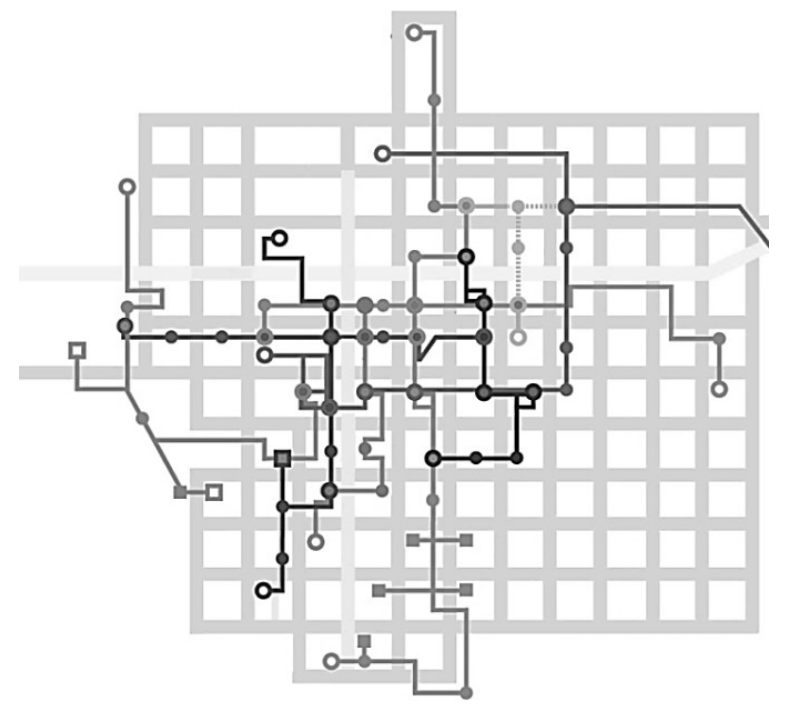

Fig. 2. SkyWay in Minneapolis (http://millcitytimes.com/news/still-open-skyway-operationssummary.html) 
With time, the SkyWay has significantly outrun its Saint Paul's predecessor. Today, the SkyWay system in Minneapolis links 47 city quarters, connecting existing objects - historical buildings and sites of modern social life, and extending over 8 miles $(13.5 \mathrm{~km})$, which makes it the largest continuous pedestrian system in the world. However, from the architectural point of view, Saint Paul's pedestrian system looks more integral than SkyWay system in Minneapolis [19].

The larger part of pedestrian systems in Asia is formed by overground walkways. Overground pedestrian system in Hong Kong (China) is virtually a multilevel city with elevated public spaces, connecting housing, businesses, offices, and parkings into a single megastructure dominating the public transportation levels [20].

Mumbai Skywalkin India consists of 36 overground pedestrian walkways. This system is a part of the effort on improving traffic situation in the city. Initially, the project intended to construct 50 overground pedestrian walkways. However, due to construction problems and local criticism, the number of walkways was cut down [21].

This study made it possible to solve the very important architectural problem -to analyzescholarly works on architectural planning principles of MPS formation. In the global practice,multilevel public spaces serve as means of urban environment organization and represent anintertwining of three systems: transportation system, pedestrian system, and urban fabric.

1. Land marking and land or property ownership.In North America,buildings and skyways are usually owned by companies and, therefore, cannot be deemed public [22]. However, in Asia, overground pedestrian systems are built by municipal administrations, and connect privately owned buildings and businesses with municipal property [23].

2. Versatility of MPS development. A multilevel public space can act not only asa system of underground or overground pedestrian crosswalks [24]. They can also serve several other functions as well. In North America such systems are often used as enclosed footbridges to connect buildings, recreational areas, to raisea city's parks, gardens, etc. over the ground level. The spaces within the buildings, formed by interconnections of skywalks, are often given to retail businesses and can act as shopping centers. In Asia, MPS systems are mostly used to provide safe access to public transit nodes [25].

3. Architectural planning. In the USA, the first floors of skyscrapers often act as the elements of overground pedestrian system. Skyway systems are formed by pedestrian bridges usually located not higher than the $3^{\text {rd }}$ floor above the ground level. In Asia such systems often represent an independent integral structure. Thus, we can consider the reviewed structures as an integral architectural and planning element of a city, forming the unique look of a certain territory with its characteristic features [26].

4. Economical effectiveness.According to available publications, an MPS system is able to determine price formation of property in city districts, promoting the development of central parts of cities and forming their identity [27]. Aside from pedestrians' comfort and safety, the main drivers for development and realization of overground pedestrian systems both in America and in Asia are the need to reduce traffic congestions on the roads, reduce air pollution from vehicles, and to protect pedestrians from transport noise[28]. Complex numerical simulation studies were conducted in several cities to analyze pedestrian systems and to optimize networks of overground pedestrian networks.

5. Historical and cultural aspects. The analysis of historical evolution of multilevel public spaces shows that such spaces emerged in a response to certain social needs of urban life. Over the last decades the need in multilevel public spaces has risen sharply [29].Conservation, restoration, renovation, and formation of new MPS's, growth of their social importance and relevance are dictated by increasing automobilization and social changes in society. Both in America and Asia overground pedestrian systems have positive effect on historical objects, providing a laconic connection and visual communication between historical buildings and modern architecture [30]. 


\section{Discussion}

In this study we have reviewed various multilevel objects in North America and Asia. In America such objects are usually represented by overground and underground pedestrian systems, while in Asia such objects are mostly the overground systems consisting of crosswalks.

We have established that an MPS can act as the continuous system of urban pedestrian traffic, developing within the framework of factors identified here:

- land marking and land or property ownership;

- versatility of MPS development;

- architectural planning;

- economical effectiveness;

- historical and cultural aspects.

According to the results of the study, an MPS certainly has development perspectives as pedestrian systems become a dominant feature of future cities.

\section{Conclusions}

1. Authors have studied and summarized considerable theoretical and practical material on formation of multilevel public space as a means of urbanistic architecture.

2. The study has made it possible to identify main architectural planning factors influencing the formation of multilevel public spaces.

3.Authors conducted the comparative analysis of multilevel public spaces in North America and Asia, demonstrating the perspectives of MPS development as pedestrian systems become a dominant feature of future cities.

\section{References}

1. R. Cao, S. El-Tawil, A.K. Agrawal. Miami Pedestrian Bridge Collapse: Computational Forensic Analysis, Journal of Bridge Engineering, 251, (2020). DOI: 10.1061/(ASCE)BE.1943-5592.0001532.

2. E.S. Ponomarev, K.S. Ivshin. Territorial branding project strategy, Izvestiya KGASU, 4 (50), (2019)

3. L.Yang, Koen H. van Damc. Integrated design of transport infrastructure and public spaces considering human behavior: A review of state-of-the-art methods and tools, Frontiers of Architectural Research 84, (2019). DOI: 10.1016/j.foar.2019.08.003.

4. F. Li, X. Liu, X. Zhang, D. Zhao, H. Liu, C. Zhou, R. Wang, Urban ecological infrastructure: an integrated network for ecosystem services and sustainable urban systems, Journal of Cleaner Production 163, (2017). DOI: 10.1016/j.jclepro.2016.02.079.

5. R.K. Muhitov. The relevance of functional monitoring of the pedestrian zone of the historic town (on the example of the Bauman Street in Kazan, Izvestiya KGASU 1 (43), (2018).

6. Y. Hong. Actual condition of Seoullo 7017 overpass regeneration project based on fieldsurveys, Frontiers of Architectural Research 7, 3 (2018). DOI: 10.1016/j.foar.2018.06.007.

7. M. Guo, K.H. van Dam, N.O. Touhami, R. Nguyen, F. Delval, C. Jamieson, N. Shah. Multi-level system modelling of the resource-food-bioenergy nexus in the global south, Energy 197, (2020). DOI: 10.1016/j.energy.2020.117196.

8. A. Shakibamanesh, M. Ghorbanian. Effects of urban spatial configurations and physical structures on pedestrians' perception of subjective duration, Interaction Design and Architecture(s) 36, (2018). DOI: 10.1016/j.foar.2017.05.004.

9. Sh. Zhao, A. Ohgai. Asian City Planning for a Sustainable Urban Society, Frontiers of Architectural Research 44, (2015). DOI: 10.1016/j.foar.2015.10.001.

10. Y.A. Zakirova, T.S. Hakimova. Influence of the principles of futurological concepts on 
urban planning of the XX-XXI centuries, Izvestiya KGASU 1 (43), (2018).

11. K.-I. Tanaka, R. Miyashiro, Y. Miyamoto. A layered network formulation for the safe walking route design problem, Journal of Design, Systems and Manufacturing 12 (3), (2018). DOI: 10.1299/jamdsm.2018jamdsm0065.

12. G. Watts. Tranquillity Trails for urban areas, Urban Forestry and Urban Greening 29, (2018). DOI: 10.1016/j.ufug.2017.11.015.

13. L. Lavrov, F. Perov, A. Eremeeva. Methods of the development of pedestrian traffic routes in the historical center of Saint Petersburg, Transportation Research Procedia 36, (2018). DOI: 10.1016/j.trpro.2018.12.117.

14. A. Al-Haramia, R. Furlanb. Qatar National Museum-Transit oriented development: The masterplan for the urban regeneration of a 'green TOD', Journal of Urban Management, 9 (1) (2018). DOI: 10.1016/j.jum.2019.09.003.

15. O.A. Lisina. Historical preconditions for creation of multi-level pedestrian spaces, Akademicheskiy vestnik Uralniiproyekt RAASN, (2016).

16. E.A. Wagner Principles of formation of the architectural environment of pedestrian spaces in the context of the current urban development from the standpoint of sustainable urban development, Gradostroitel'stvo, (2016).

17. N.V. Sokolova, O.I. Sukhova. Urban pedestrian system and their development in modern urban planning concepts, Tvorchestvo i sovremennost', (2019).

18. L. Lavrov, A. Surovenkov. Problem of the pedestrian route system in the center of SaintPetersburg, Topical Problems of Green Architecture, Civil and Environmental Engineering, TPACEE, (2019). DOI: 10.1051/e3sconf/202016404025.

19. O. Kokorina, F. Perov, R. Mangushev. Principles of the formation of tourism and recreation complexes (example of Rozhdestveno, Leningrad Oblast, Russia), Topical Problems of Green Architecture, Civil and Environmental Engineering, TPACEE, (2019). DOI: $10.1051 / \mathrm{e} 3$ sconf/202016404018.

20. L.M. Enikeeva, V.Y. Chichkanova, E.I. Prokofev. Urbanized landscape architecture in the formation of a modern city, Izvestiya KGASU, 2 (44) (2018).

21. A. Sharma. Urban greenways: Operationalizing design syntax and integrating mathematics and science in design, Frontiers of Architectural Research 4, 1 (2015). DOI: 10.1016/j.foar.2014.11.002.

22. G. Senes, R. Rovellia, D. Bertonib, L. Aratac, N. Fumagallia, A. Toccolinia. Factors influencing greenways use: Definition of a method for estimation in the Italian context, Journal of Transport Geography 65, (2017). DOI: 10.1016/j.jtrangeo.2017.10.014.

23. J. Sims-Gouldab, D.L. Race, N. Vasayaa, H.A. McKaya. A new urban greenway in Vancouver, British Columbia: Adolescents' perspectives, experiences and vision for the future, Journal of Transport \& Health 15, (2019). DOI: 10.1016/j.jth.2019.100620.

24. J. Cu. Building three-dimensional pedestrian networks in cities, Underground Space (2020). DOI: 10.1016/j.undsp.2020.02.008.

25. J. Zacharias, J. He. Hong Kong's urban planning experiment in enhancing pedestrian movement from underground space to the surface, Tunnelling and Underground SpaceTechnology 82, (2018). DOI: 10.1016/j.tust.2018.07.025.

26. E.V. Pokka, A.F. Gafiyatullina. Modern trends in the formation of tourist centers in the context of the development of tourist centers, Izvestiya KGASU 2 (52), (2020).

27. L.A. Akhmetshina, G.N. Aidarova. Features of formation of the architectural environment of pedestrian streets of peripheral («sleeping») areas on the example of Kazan, Izvestiya KGASU 2 (48), (2019).

28. K. Liu, K.W.M. Siub, Xi Y. Gongc, Y. Gaoc, D. Luc. Where do networks really work? The effects of the Shenzhen greenway network on supporting physical activities, Landscape and Urban Planning 152, (2016). DOI: 10.1016/j.landurbplan.2016.04.001.

29. K.W.M. Siu, C.H. Lo, Y.L. Wong. Inclusive Design for Recycling Facilities: Public Participation Equity for the Visually Impaired, International Conference on Human Systems Engineering and Design: Future Trends and Applications, IHSED, Munich, Germany, (2019).

30. E.S. Ponomarev. Vertical future of cities, International journal of advanced studies $\mathbf{8}$, 4$2(2018)$ 